\title{
Students' Views on the Use of a Virtual Educational Museum
}

\author{
Maria Kampouropoulou ${ }^{1}$, Persa Fokiali ${ }^{2}$, Ioanna Efstathiou ${ }^{1}$, Theodoros Koutris ${ }^{1} \&$ Efstathios $_{\text {Stefos }}{ }^{1}$ \\ ${ }^{1}$ Department of Primary Education, University of the Aegean, Rhodes, Greece \\ ${ }^{2}$ Department of Preschool Education Sciences and Educational Design, University of the Aegean, Rhodes, \\ Greece \\ Correspondence: Efstathios Stefos, Department of Primary Education, University of the Aegean, Dimokratias 1, \\ 85100, Rhodes, Greece. Tel: 30-224-109-1451. E-mail: estefos@aegean.gr
}

Received: January 27, 2015 Accepted: April 30, 2015 Online Published: June 26, 2015

doi:10.5539/res.v7n11p1 URL: http://dx.doi.org/10.5539/res.v7n11p1

\begin{abstract}
Culture and Education are two concepts intertwined together as, through Education, formal and informal, forms and elements of Culture are developed. Education is therefore one of the most important factors of enhancement, promotion and preservation of cultural heritage through the development of appropriate educational "spaces" directed to different social groups. The research took place in Greece over the Academic year 2013-14 and it was carried out nationally aiming students' depiction of views and attitudes on the use of a virtual educational Museum. The total number of respondents nationwide was 22902 students of first, second and third grade of High School.
\end{abstract}

Keywords: virtual museum, educational implications and applications

\section{Introduction}

In recent years considerable efforts are made to improve the educational process in environments that are very innovative, attractive and with the assistance of the New Technologies of Information and Communication. Inside the huge volume of information sources, the teaching practice has expended and most educational systems aim at improving and upgrading the educational process through technological learning environments (Yoram, 2007). According to the Association of Educational Communications and Technology, the educational technology based on virtual reality is the application of knowledge, systems and techniques to improve human learning (AECT, 1977).

\section{Aims of the Research}

World Wide Web (WWW) and cyber (cyberspace), changed the dynamic concept of information, knowledge and communication. The critical literacy in combination with new technologies and design tailored educational software and applications using multimedia tools, are the main subject of educational technology. The appropriate use of educational software in the learning process and students' familiarization in these tools ensures their equal access to good education (Kokkinos, 2003).

The goals of the research were:

- To determine whether the educational virtual museum can contribute to an interdisciplinary approach to the subjects taught secondary education and particularly in high school.

- To test students' knowledge at the level of folk Art and Culture.

- Carry out a correlation of their estimates, with demographic data and the level of education of their parents.

- To make a final assessment of the pedagogical and educational dimensions that a virtual, educational Museum of Art and Culture might would have for students (Kampouropoulou et al., 2013).

\section{The Virtual Educational Museum in the Frame of Constructivism}

Learning theories and various educational models related to empirical, experiential and discovery nature characterize a virtual environment as educational when focuses on teaching, such as the constructivism, multiple intelligences, experiential learning, social learning, etc. (Dede, 1995).

Gardner contends that museums play a very important role in education as well as they offer the opportunity for 
students to focus on multiple aspects of intelligence and, beyond the barriers of the public education system, is usually confined to the linguistic and logical-mathematical intelligence (Gardner, 1993).

In a museum environment, real or virtual, based on the theory of constructivism:

- The learning process in which the student is involved is essentially an act of knowledge construction as a variety of experiences, interactions and activation of all senses is offered.

- There is an opportunity for a student to "build" his/her own personal knowledge for each exhibit / object and shape both individual conclusions.

- There is attempting to resolve problems in attractive environments with the students not as passive recipients, but actively involved in the learning process.

- The learning environment transforms the educational leader in the preparation of appropriate materials and activities able to allow students to interact and build knowledge (Hein, 1995).

Virtual Museums "eliminate" any spatial and temporal context and the significance of museum experience is utilized with multiple means via representation or viewing objects, buildings, spaces etc. (Efstathiou \& Stefos, 2013). The use of new technologies, especially the experiential Technologies, including virtual reality, now provides the opportunity for the public to visit a virtual museum to explore, wander the exhibits, and acquire multitude of experiences and knowledge (Falk \& Dierking, 2000).

\section{The Survey}

The research took place during the academic year 2013-2014. 22902 Greek students of the first, second and third grade of High School participated in a survey and answered a questionnaire in order to investigate their views on the use of a virtual educational museum. In the frame of this research, we used the software SPSS v.20 and SPAD v.4.5, offered by the School of Humanities of the University of the Aegean.

\section{The Results of the Survey}

$47.96 \%$ of the students were boys and $52.04 \%$ were girls. When asked "Which grade of High school do you attend?" $0.10 \%$ didn't answer. $31.53 \%$ were in the first grade, $33.49 \%$ in the second grade and $34.87 \%$ in the third grade.

When asked "Do you believe that if somebody knows the culture of his place he is more connected with it?" 4.83\% answered that they completely disagree, $17.84 \%$ that they disagree, $34.53 \%$ that they neither agree nor disagree, $27.95 \%$ of the students agreed, $14.35 \%$ said that they strongly agree and $0.5 \%$ of the students didn't answer.

When asked "Do you know occupations related to art and culture?" $6.72 \%$ answered that they completely disagree, $22.67 \%$ that they disagree, $33.29 \%$ that they neither agree nor disagree, $23.04 \%$ of the students agreed, $13.65 \%$ said that they strongly agree and $0.64 \%$ of the students didn't answer.

When asked "Do you believe that the cultural heritage of a place should be preserved?", $3.55 \%$ answered that they completely disagree, $9.19 \%$ that they disagree, $19.20 \%$ that they neither agree nor disagree, $25.43 \%$ of the students agreed, $41.52 \%$ said that they strongly agree and $1.09 \%$ of the students didn't answer.

When asked "A virtual museum could help you to know better the culture of a place?" $4.59 \%$ answered that they completely disagree, $16.72 \%$ that they disagree, $37.06 \%$ that they neither agree nor disagree, $28.14 \%$ of the students agreed, $13.06 \%$ said that they strongly agree and $0.43 \%$ of the students didn't answer.

When asked "Do you believe that a virtual museum will help you to get information about the culture of a place?", $4.82 \%$ answered that they completely disagree, $16.74 \%$ that they disagree, $40.01 \%$ that they neither agree nor disagree, $25.94 \%$ of the students agreed, $12.29 \%$ said that they strongly agree and $0.20 \%$ of the students didn't answer.

When asked "Do you believe that a virtual museum with exhibits from the history of a place will help you gain a greater understanding of this history?", $3.80 \%$ answered that they completely disagree, $16.56 \%$ that they disagree, $34.22 \%$ that they neither agree nor disagree, $30.01 \%$ of the students agreed, $15.07 \%$ said that they strongly agree and $0.34 \%$ of the students didn't answer.

When asked "Do you believe that a virtual museum will help you to perform your school homework?", 6.39\% answered that they completely disagree, $19.71 \%$ that they disagree, $32.49 \%$ that they neither agree nor disagree, $25.26 \%$ of the students agreed, $15.68 \%$ said that they strongly agree and $0.48 \%$ of the students didn't answer.

When asked "Would you visit a virtual museum through the internet?", $11.07 \%$ answered that they completely disagree, $21.18 \%$ that they disagree, $28.96 \%$ that they neither agree nor disagree, $23.15 \%$ of the students agreed, 
$14.21 \%$ said that they strongly agree and $1.32 \%$ of the students didn't answer.

When asked "Do you believe that it would be interesting to visit a virtual museum?", $6.10 \%$ answered that they completely disagree, $17.10 \%$ that they disagree, $31.64 \%$ that they neither agree nor disagree, $25.32 \%$ of the students agreed, $18.50 \%$ said that they strongly agree and $1.34 \%$ of the students didn't answer.

When asked "Would you like there to be a virtual museum that will present your local culture all over the world through the internet?", $5.62 \%$ answered that they completely disagree, $12.92 \%$ that they disagree, $25.15 \%$ that they neither agree nor disagree, $27.43 \%$ of the students agreed, $28.41 \%$ said that they strongly agree and $0.48 \%$ of the students didn't answer.

When asked "Would you like to participate in the construction of a virtual museum that would present the cultural heritage of your hometown?", $10.11 \%$ answered that they completely disagree, $18.88 \%$ that they disagree, $25.11 \%$ that they neither agree nor disagree, $22.11 \%$ of the students agreed, $23.40 \%$ said that they strongly agree and $0.40 \%$ of the students didn't answer.

\section{The Results of the Multidimensional Analysis}

The analysis of the results used the Multidimensional Data Analysis, which allowed for the presentation of the differentiation criteria of the students and for their classification into clusters according to the common answers they have provided during the survey. This way, we investigated the results of all the answers interrelation and we showed that what plays a major role is not the frequency of the emergence of a variable/characteristic but the combination of a group of variables at the same time that leads to the emergence of classification criteria. The methods that we used are the Multiple Correspondence Factor Analysis, which defines the differentiation criteria of the students and the Hierarchical Clustering, which presents the students' clusters according to their common answers and characteristics (Benzécri, 1992).

\subsection{The Students' Differentiation Criteria}

The results of Multiple Correspondence Analysis present the factorial axes, which are the differentiation criteria of the students. These differentiation criteria are presented as oppositions in order of significance and correspond to the axes of the Correspondence Analysis (Athanasiadis, 1995). The elements that differentiate the 22902 students that participated in the survey are defined by the three criteria of differentiation (three factor axes) that follow.

\section{First differentiation criterion (first factor axis/inertia percentage 6.04\%):}

On one hand, the 1st differentiation criterion consists of students who answered that they do not want to visit a virtual museum through the internet, they do not want to participate in the construction of a virtual museum that would present the cultural heritage of their hometown and they are not interested in visiting a virtual museum. On the other hand, there are students who would very much like it if there was a virtual museum that would present all over the world their local culture through the internet. These students believe that a tour in a virtual museum would be very interesting for them and they think that a virtual museum with exhibits of the local history would help them to understand this history.

Second differentiation criterion (second factor axis / inertia percentage $4.21 \%$ ):

In the 2 nd factor axis, on one hand there are students who believe that a virtual museum would help them very much to get information about the culture of a place and know better this place. These students answered that they would very much like to visit a virtual museum through the internet and learn this way the culture of a place. On the other hand, there are students who believe that a virtual museum would help them to know the culture of a place. These students believe that a virtual museum with exhibits of the history of a place would help them at a moderate level to understand this history and they answered that a virtual museum could help them to do their homework.

Third differentiation criterion (third factor axis/inertia percentage $2.59 \%$ ):

In the 3rd third criterion, on one hand there are students who believe that a virtual museum would help them at a low level to get information about the culture of a place and they answered that they are not very much interesting in visiting a virtual museum. These students believe that a virtual museum with exhibits of the history of a place would help them at a low level to understand this history. However, in this group there are students who believe that a virtual museum would help them very much to get information about the culture of a place and they answered that a virtual museum with exhibits of the history of a place would help them very much to understand this history. These students answered that they would very much like it if there was a virtual museum that would present their local culture all over the world through the internet. 


\subsection{The Results of the Hierarchical Clustering}

Looking for a clustering of the students' views we used the Ascending Hierarchical Classification. This method presents the centers of the clusters on the factor levels, while at the same time shows the groups of answers to the questions, aiming to a complete interpretation of the differences among the groups.

The Hierarchical Clustering led to the formation of four clusters of students, which are presented in Figure 1 that follows.

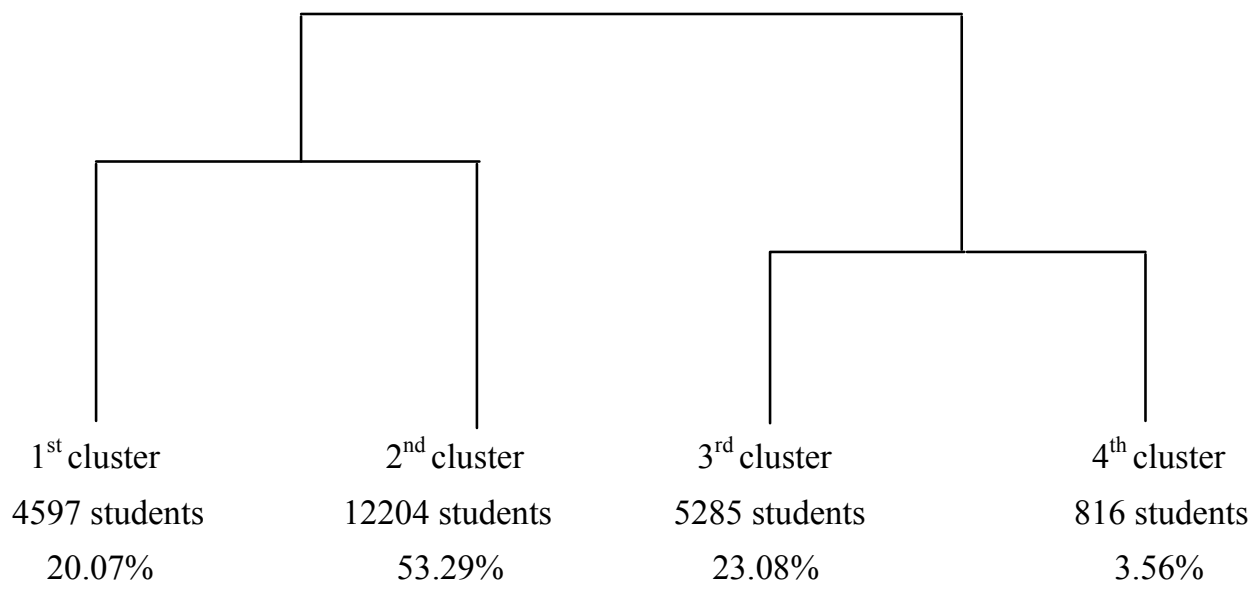

Figure 1. The Hierarchical Clustering

First cluster (4597 students / $20.07 \%$ of the sample):

The students of the $1^{\text {st }}$ cluster believe that a virtual museum with exhibits of the history of a place would help them very much to understand this history. These students answered that they would like very much to visit a virtual museum through the internet and learn about professions related to art and culture.

Second cluster (12204 students $/ 53.29 \%$ of the sample):

The students of the $2^{\text {nd }}$ cluster believe that a virtual museum would help them to get information about the culture of a place and they are interested in visiting a virtual museum. These students answered that they would very much like it if there was a virtual museum that would present their local culture all over the world through the internet.

Third cluster ( 5285 students $/ 23.08 \%$ of the sample):

The $3^{\text {rd }}$ cluster consists of students who believe that a virtual museum can help them at a low level to get information about the culture of a place and to understand the history of this place. These students answered that they are not very much interested in visiting a virtual museum through the internet.

Fourth cluster ( 816 students $/ 3.56 \%$ of the sample):

The $4^{\text {th }}$ cluster consists of students who answered that are not interested at all in a tour of a virtual museum and they do not believe that a virtual museum would help them to get information about the culture of a place. These students do not believe that a virtual museum with exhibits of the history of a place would help them to understand its culture.

The differences among the clusters are presented in Figure 2. In this figure the position of centers of gravity of the four clusters highlight the similarities and the differences between the students of each cluster. 


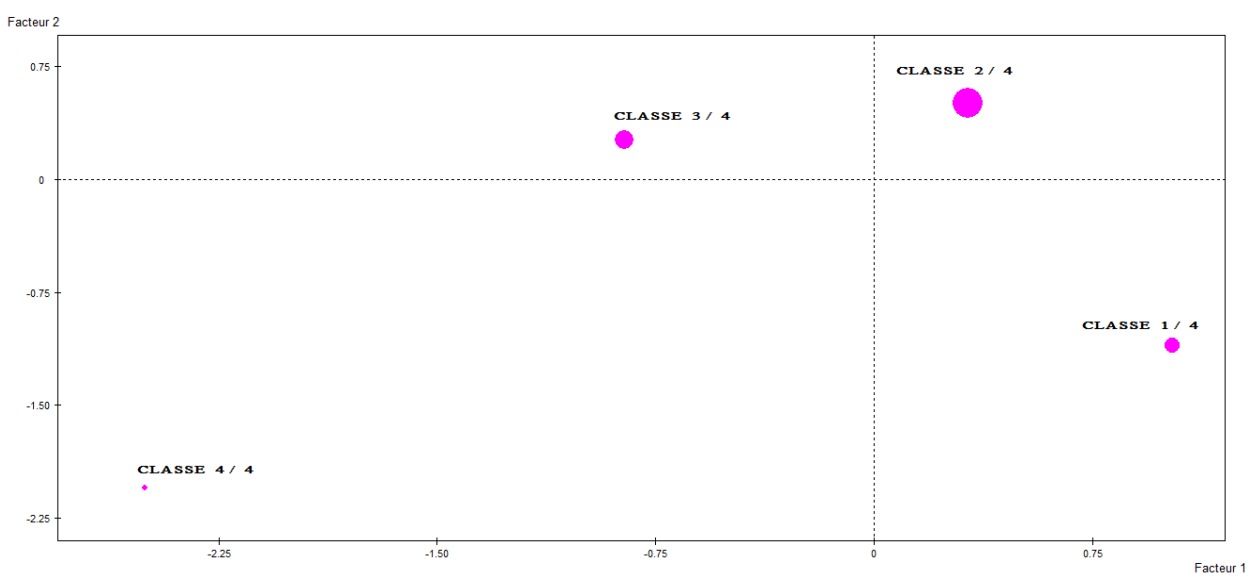

Figure 2. The graph of the Correspondence Analysis

\section{Conclusions}

Virtual reality has become a popular and attractive learning environment. It is a cognitive tool, attractive and impressive for learners on condition, as Chen claims that, the design of these environments is based on learning theories and models, which enhance learning and identified ways that could make it effective for learners of different skills (Chen, 2006).

The survey results led to the conclusion that the widespread application of a virtual educational museum at school with a view to developing construction skills plays a great role, when using modern digital environments specially formulated for Secondary Education students. The research leading to the specific conclusions can be a starting point for further analysis, deeper and specifically and a new challenge for further investigation (Athanasiadis \& Stefos, 2006).

\section{References}

Association of Educational Communications and Technology. (1977). Educational Technology: Definition and Glossary of Terms. Washinghton, DC: Author.

Athanasiadis, I. (1995). Correspondence Analysis and Hierarchical Classification (New Technologies Editions, pp. 51-56).

Athanasiadis, I. \& Stefos, E. (Eds.). (2006). Interdisciplinary technological approaches. Applications in the High School of Ialyssos (pp. 36-40). Municipal library of Ialyssos.

Benzécri, P. (1992). Correspondence Analysis Handbook. New York: Dekker.

Chen, C. J. (2006). The design, development and evaluation of a virtual reality based learning environment. Australasian Journal of Educational Technology, 22(1), 39-63.

Dede, C. (1995). The evolution of constructivist learning environments: Immersion in distributed, virtual worlds. Educational Technology, 35(5), 46-52.

Efstathiou, I., \& Stefos, E. (2013). The lesson of Local History in High School. The contribution of the Virtual Museum. In K. Glezou \& N. Tzimopoulos (Eds.), Proceedings of the $7^{\text {th }}$ Panhellenic Conference for the Information and Communication Technologies in Education "Utilization of Information Technology and Communication in Teaching Practice” (p. 6). Syros.

Falk, J. H., \& Dierking, L. D. (2000). Learning from Museums: Visitor Experiences and the Making of Meaning (p. 147). London.

Gardner, H. (1993). Frames of Mind: The Theory of Multiple Intelligences (10th Anniversary Edition). NY: Basic Books.

Hein, G. (1995). The constructivist Museum. Journal of Education in Museums, 15.

Kampouropoulou, M., Fokiali, P., Stefos, E., \& Efstathiou, I. (2013). The Virtual Museum in Educational Practice, Review of European Studies, 5(4), 120-129. http://dx.doi.org/10.5539/res.v5n4p120

Kokkinos, G. (2003). Science, Ideology, Identity: The course of history in the constellation, supranational and 
globalization (pp. 323-324). Athens, Routledge.

Yoram, E. (2007). Teaching Online: Survival for the effective teacher. Publisher ACM.

\section{Copyrights}

Copyright for this article is retained by the author(s), with first publication rights granted to the journal.

This is an open-access article distributed under the terms and conditions of the Creative Commons Attribution license (http://creativecommons.org/licenses/by/3.0/). 